\title{
Portable Smart Phone Charger Using Human Mechanical Energy by Gear Train with Hand Crank
}

\author{
Rocky Chakma ${ }^{1}$, Thanarat Chawaphan ${ }^{2}$, Khandakar Abdulla Al Mamun ${ }^{3}$, Amit \\ Chakma $^{4}$, Sajid Harun ${ }^{5}$ \\ ${ }^{1,2}$ (School of Automation Science \& Engineering, South China University of Technology, China) ${ }^{3}$ (Department \\ of EEE, International Islamic University Chittagong, Bangladesh) \\ ${ }^{4,5}$ (Department of EEE, Chittagong University of Engineering and Technology, Bangladesh)
}

\begin{abstract}
Mobile phone is our means to remain connected. While the phones have progressively got more powerful processors and large touch screen interfaces, their power requirement has increased correspondingly. Unfortunately, battery technology has not been growing at a comparable pace. Hence, there is a need to frequently charge the batteries. While travelling, people face a common problem of charging electronic appliances. Our solution to this problem is mechanical based hand crank charger. Mechanical hand crank mobile charger is a device that utilizes mechanical energy, converts it into electrical energy and charges the mobile. It doesn't require any electrical source. Also by going for this alternative source of energy we can reduce the human footprint on Earth as we are using human effort instead of conventional electricity. We have used a gear train and intermediate gears for transformation of mechanical energy from hand crank to generator.
\end{abstract}

Keywords: Smart Phone Charger, Gear, Motor, Mechanical Energy.

\section{Introduction}

With ever increasing demand for energy, man has left no stone unturned in his search for the same. Many methods of extracting energy have been experimented with and the best is done to develop them. There are so many possible energy sources available for doing that. Such as: solar, wind, water, static, mechanical etc. These types of energy sources are not suitable for all situations. Some has distinctive advantages over others and some has disadvantages also. At present, scientists and manufacturers are still trying to improve and meet our ongoing energy demands for portable electronic devices. Of all the thus experimented methods of extraction, generation of electrical energy from mechanical energy proved to be the most efficient. It's the easiest way to generate power. For mechanical part gear, pulley, lever system etc can be used. But among them, gear system or gear box train system is easiest way to generate power in less space. Using hand crank to wind up the gear box is most common way. This mechanism is used back in the past to generate short amount of power in old telephone, gramophone and old radio. In World War II, this wind up mechanism was extensively used in searchlights, sirens, radio communications etc. Still, this mechanism is very useful now-a-days. We have explored other methods and finally landed up with this solution: Portable hand crank mobile charger. In general cell phone battery requires $3.6-5$ volts dc and $180-700 \mathrm{~mA}$ current for charging. Since we are using a 6volt dc motor as generator in reverse we will be getting the desired output easily.

Weston L. Moyers and H. Scott Coombe [1] developed a hand crank system, with the potential for both military and commercial application, is under development to meet existing and emerging dismounted soldier power needs. Nikhil Kumar Jain, V Aravind, Eranki V S Krishna Prasad, Kalyan Chakravarthy [2] have designed a virtual prototype mobile charger based on compound gear train. Thad Starner and Joseph A. Paradiso [3] studied the all possible human generated power for mobile electronics. They studied the alternate power generation from people, power from arm motion, respiration, blood pressure, body heat etc. Robert Dunn and Adam Weber [4] designed and built a portable hand crank generator for cell phones. The portable generator also includes a bright LED that functions as a flashlight. Ayush R Jain and Chinmay V Harmalkar [5] developed a Hybrid Mechanical Charger and it was successfully implemented on a Nokia phone. Charging of a mobile phone was done by both hand crank and windmill mechanism. It was found that the rate of charging from Hybrid Mechanical Charger is equivalent to the normal charger. Edwar Romero [6] harvested energy for a small scale from the surroundings including machine motions, vibrations, temperature gradient etc. $\mathbf{L i}$ Linqiang [7] presented a Portable Hand Crank Cell Phone Charger with an LED light that can be used anywhere. Also this device would convenient when on extended outdoor trips. This device would come in handy when there is a power outage and you need a flash light too, it always seems like the batteries are dead in flash lights. This devise is both practical and convenient. Alfred Berrios, Tristan Byers, Melanie Cromer \& Michael Matthews [8] presented the UCF combines kinetic and solar energy to a portable battery charging 
system in order to maximize the power for a range of handheld devices. This paper presents the design and implementation of an efficient charging system which utilizes kinetic, solar, and grid power to charge common electronics devices. The small size of the UCF makes it easy to transport within backpacks for trips. In short word, we are trying to create a portable hand crank device that can be used in emergency situations to produce power where electricity is not available.

\section{Design Procedure}

This project is done in a way of electro-mechanical combination. So there is two part of design procedure one is mechanical and another one is electrical. Here is the thorough description of the procedure.

\section{A. Block Diagram}

Fig. 1 shows the total block diagram of the project and its operation.

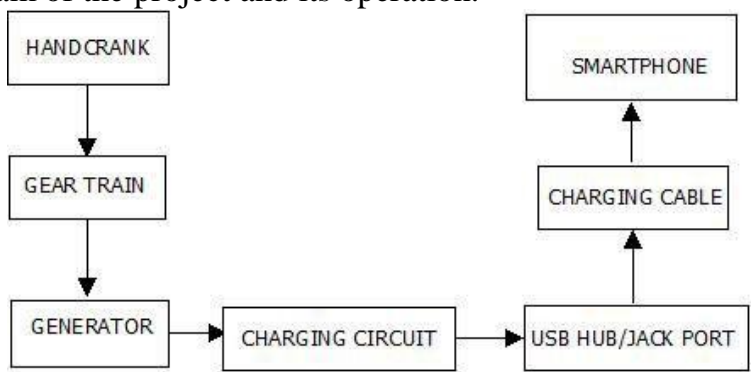

Figure 1: Block diagram

\section{Gear details}

Total no. of Gears used $=5$

One of them is driver gear another one is driven gear and other three of them are intermediate gears.

\section{Driver gear}

This gear is attached with the hand crank which is to be rotated by hand.

No. of teeth of driver gear $=35$

\section{Intermediate Gear}

These gears are set in between the driver and driven gears.

No. of gears $=3$

No. of teeth in second gear $=12 / 35$

No. of teeth in third gear $=12 / 60$

Here 12/35 means the upper part (shown on image) has 12 teeth and the lower part has 35 teeth.
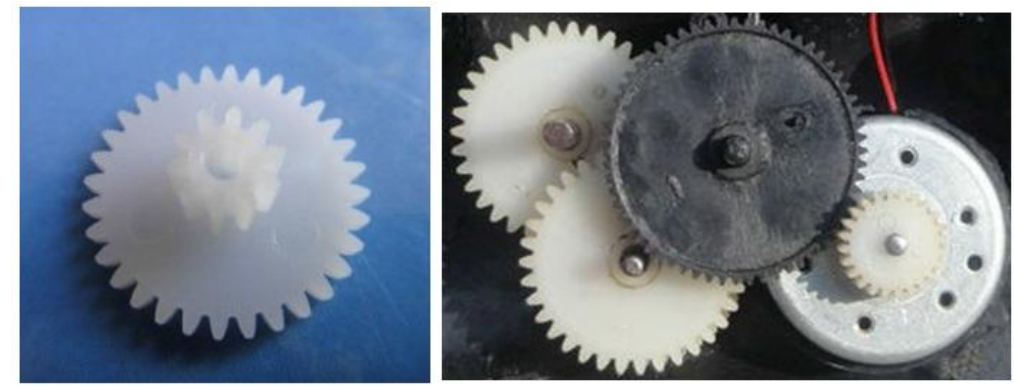

Figure 2: Gear with lower \& upper part having different no. of teeth

Figure 3: Gear Train

\section{Driven gear}

Fig. 2 and Fig. 3 shows the gears which are fixed with the dc motor shaft which will be used as small generator.

No. of teeth of driven gear $=24$

\section{Gear Train}

In the gear train the gears are arranged in such a manner that they can be run efficiently.

\section{Gear Ratio}

The gear ratio can be calculated directly from the numbers of teeth on the gears in the gear train. The torque ratio of the gear train, also known as its mechanical advantage, is determined by the gear ratio. The speed ratio and mechanical advantage are defined so they yield the same number in an ideal linkage.

Gear ratio $=($ no. of teeth of gear A / no. of teeth of gear B $)$

According to this formula the gear ratio of the whole gear train is calculated step by step

DOI: $10.9790 / 1676-1203012025 \quad$ www.iosrjournals.org $21 \mid$ Page


below:

1. Gear ratio of driver gear and one intermediate gear $=35 / 12=2.92$

2. Gear ratio among two intermediate(identical) gears $=35 / 12=2.92$

3. Gear ratio among two intermediate(different) gears $=35 / 12=2.92$

4. Gear ratio of one intermediate gear and driven gear $=60 / 24=2.50$

Therefore, for one full rotation of the hand crank the revolution of the shaft of the motor(which is used as small generator) will be $=2.92 \times 2.92 \times 2.92 \times 2.5=62.24$ (approx.)

times.

i.e. nearly 62 times the motor shaft will rotate if the hand crank is fully rotated once.

Now, this will help in calculating the rpm of the motor.

If the hand crank fully is rotated 20 times per minutes then the rpm of the motor

will be $=20 \times 62=1240$

\section{B. Generators Frequency Calculation}

\section{Frequency}

When the number of stator poles and the rotational speed of rotor are known the frequency

of ac generator can be calculated by using the formula given below

$$
\mathrm{f}=(\mathrm{P} \times \mathrm{N}) / 60
$$

Where,

$\mathrm{f}=$ the frequency of generator in hertz,

$\mathrm{P}=$ the no.of pair of stator poles,

$\mathrm{N}=$ rotational speed of rotor in $\mathrm{rpm}$ (revolution per minute),

$60=$ the formula constant that converts rpm(in minutes) into hertz(in second) According

to this formula the motor used in this project has the following frequency:

$$
\mathrm{f}=(2 \times 1240) / 60=41.33
$$

Here,

$\mathrm{P}=2$ (as the generator has 4 poles),

$\mathrm{N}=1240 \mathrm{rpm}$

Verification

Now let's check the calculation with theoretical overview If the hand crank is cranked 20

times per minutes then according to the formula given below :

$$
\operatorname{Teeth}(\mathrm{A}) \times \operatorname{Speed}(\mathrm{A})=\operatorname{Teeth}(\mathrm{B}) \times \operatorname{Speed}(\mathrm{B})
$$

Therefore we have,

$$
\text { The gear ratio }=\text { Teeth }(A) \div \text { Teeth }(B)=\operatorname{Speed}(B) \div \operatorname{Speed}(A)
$$

We know,

$$
\mathrm{rpm}=(120 \mathrm{f}) / \mathrm{p}
$$

Where, $f=$ frequency of generator,

$\mathrm{p}=$ no. of poles

In this project, $\mathrm{f}=41.33 \mathrm{~Hz}$

$p=4$ Therefore,

$$
\mathrm{rpm}=(120 \times 41.33) / 4=1239 \text { (approx.) }
$$

As we have assumed we will crank the hand at 20 times per minute. So,

Gear Ratio $=1239 / 20=61.25=62$ (approx.)

So our gear ratio is $62: 1$ which we have calculated before.

\section{Description of Mechanical setup}

Hand Crank

It is a type of crank in Fig. 4 which is rotated by human mechanical power by hand. This power is applied on the gear train.
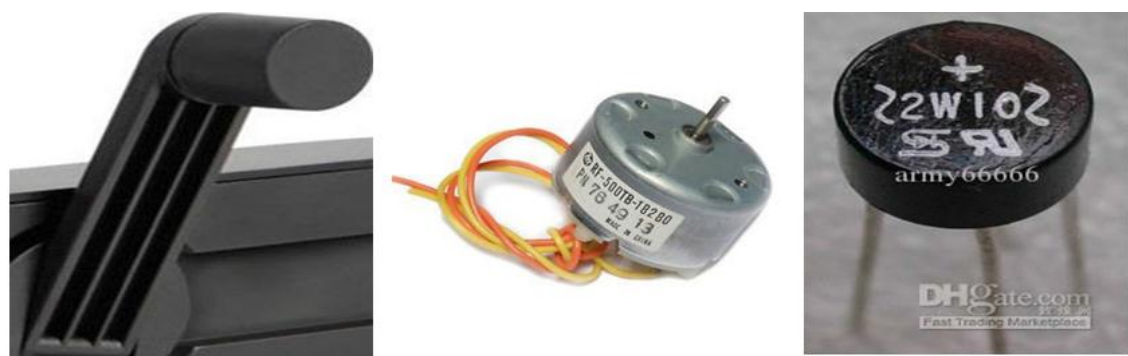

Figure 4: A typical hand crank Figure 5: DC motor as generator Figure 6: Bridge rectifier 


\section{Generator}

In this project the used generator is small dc motor(6vdc) in Fig. 5 which is reversely used as generator. The motor is run with a rpm of 1240 . The motor is not a brushless motor. So, the output current is not a good one it is about $300 \mathrm{~mA}-400 \mathrm{~mA}$.

\section{Bridge Rectifier}

Fig.6 shows the bridge rectifier is a $2 \mathrm{~W}$ rectifier. It is a round shape bridge rectifier. So easier to setup than four diode combination bridge rectifier. It is also cost effective because it's price is less than the four diode combination bridge rectifier. The heat production is also less. Here is the picture of bridge rectifier circuit.

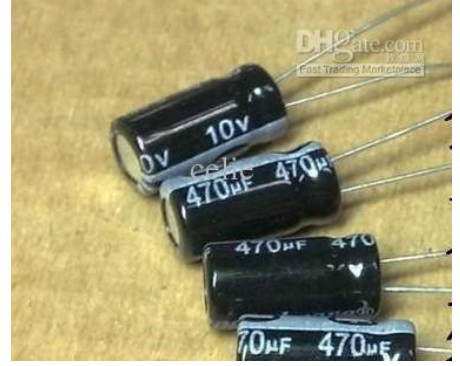

Figure 7 : Capacitor

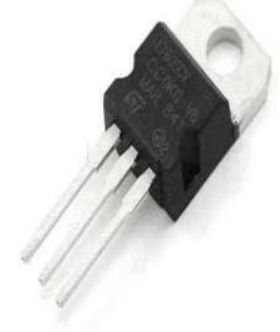

Figure 8 :Regulator

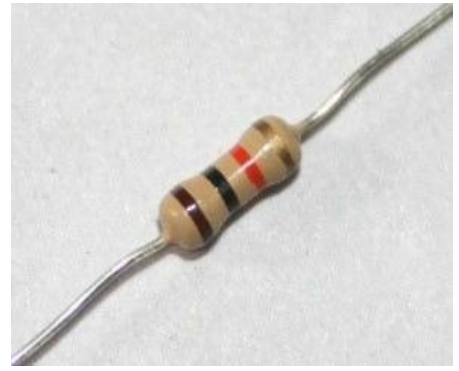

Figure 9 : Resistor

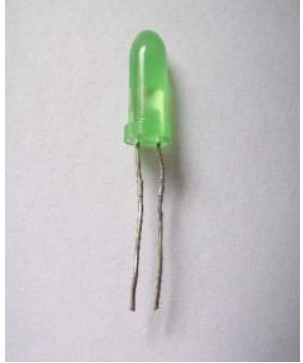

Figure 10 : LED

\section{Capacitor}

The capacitors used here are 470 uf \& 100 uf in Fig.7. These are polar rectifier as they are used in a dc circuit.

\section{Voltage regulator}

The used voltage regulator is LM7805 in Fig.8 which is able to convert the output 6.2 vdc of bridge rectifier into $5 \mathrm{vdc}$. There is a heat sink used reduce the heat produced at the regulator. Without it the regulation will lose its efficiency.

\section{Resistor}

These are two 1k resistor used in Fig.9. These two resistors are connected in series with LEDs.

\section{LED}

There are two LEDs used here one in the input and another in the output to show the circuit is working in Fig.10 and Fig. 11.

\section{Circuit Analysis}

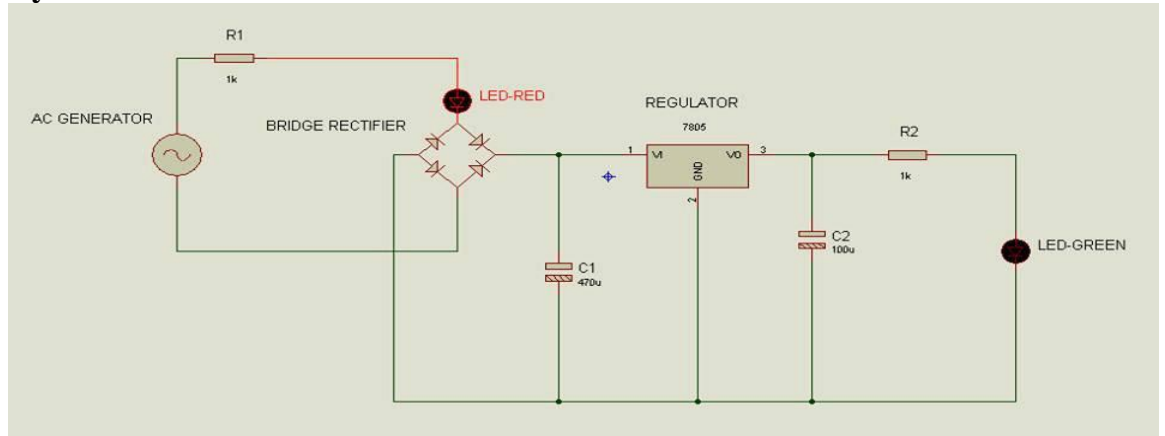

Figure 11: AC to DC conversion circuit

Fig. 11 shows a ac to dc conversion circuit. Here approximate voltage output of the generator is 7.5Vac. The circuit has one bridge rectifier, two capacitors, two resistors, one voltage regulator and two LEDs. The output of motor has fed to the ac terminals of bridge rectifier. The dc output terminals of bridge rectifier are connected to t. The dc input and dc output of voltage regulation. The capacitors are connected parallel with voltage regulator. One capacitor is connected across the dc output of the regulator and other capacitor 100 uf is connected across the dc output. The two LED's one used along with two 1k resistors, one at input (RED LED) and other at output (GREEN LED). The bridge rectifier converts the $7 \mathrm{v}$ ac output of generator into $6.2 \mathrm{vdc}$ which is fed to regulator (LM7805) which gives an output of $5 \mathrm{v}$ which is then fed to a usb hub port. The cell phone is connected by usb port starts charging when the hand crank is cranked. 


\section{A. Result}

\section{Result and Analysis}

The maximum output voltage observed at the output port (USB hub port/ jack port) is $4.96 \mathrm{vdc}$. When the motor is cranked at speed of $120 \mathrm{rpm}$ (approx.) the output voltage is nearby $5 \mathrm{vdc}$ (i.e. $4.9 \mathrm{v} \mathrm{dc}$ approximately.) The input ac voltage to the bridge rectifier is approximately $8.5 \mathrm{v}$ when the hand crank is cranked at a speed of $132 \mathrm{rpm}$, which is reduced to $4.96 \mathrm{v}$ by the voltage regulator LM7806. The data collected from the whole setup is given below:

Table 1: Data collection

\begin{tabular}{|r|c|c|c|c|}
\hline Sl. & Generator rpm & Produced input voltage & Output voltage & Outputcurrent \\
\hline 1 & 80 & $5.2 \mathrm{v}$ & $3.7 \mathrm{v}$ & $270 \mathrm{~mA}$ \\
\hline 2 & 120 & $7.3 \mathrm{v}$ & $4.96 \mathrm{v}$ & $320 \mathrm{~mA}$ \\
\hline 3 & 148 & $8.1 \mathrm{v}$ & $4.96 \mathrm{v}$ & $380 \mathrm{~mA}$ \\
\hline
\end{tabular}

The table- 1 shows if the input ac voltage across the bridge rectifier is above $6 \mathrm{v}$ output is nearby $4.5 \mathrm{v}$ or more. Fig.12 shows the practical overview of the project.

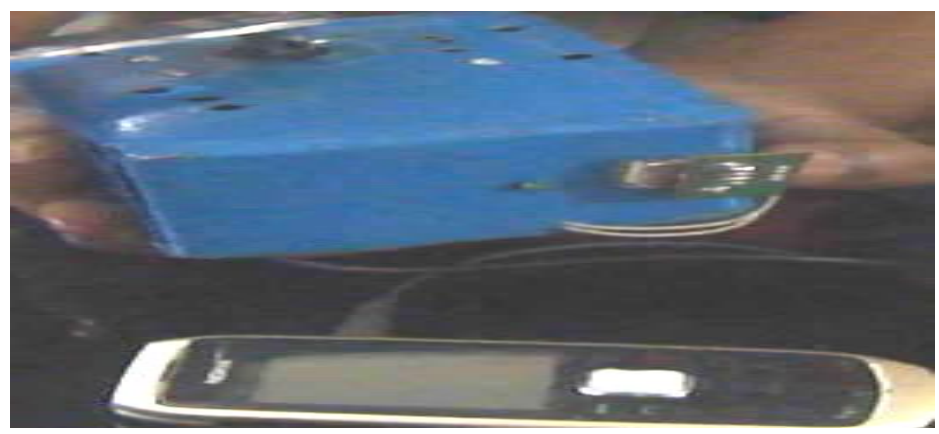

Figure 12: Practical overview

Now let us calculate the output power of the charging circuit is :

$$
\text { Pout }=\text { Vout } * \text { Iout }(\text { Max. })=(4.96 \times 380) \mathrm{W}=1.884 \mathrm{~W}
$$

Then the input power is,

\section{B. Cost analysis}

$$
\text { Pin }=\text { Vin } * \text { Iin }(\text { Max. })=8.1 \mathrm{v} \times 400 \mathrm{~mA}=3.2 \mathrm{~W}
$$

Table -2: Equipment List with Cost

\begin{tabular}{|c|c|c|c|}
\hline S1. No. & Name Of Equipment & Quantity & Cost Of Equipment \\
\hline 1 & Motor-6V dc & 1 & 60 \\
\hline 2 & Bridge Rectifier & 1 & 15 \\
\hline 3 & Capacitor-470uf & 1 & 4 \\
\hline 4 & Capacitor-100uf & 1 & 2 \\
\hline 5 & Resistor-1k & 2 & 10 \\
\hline 6 & Voltage Regulator(LM7805) & 1 & 4 \\
\hline 7 & LED & 2 & 25 \\
\hline 8 & Connecting wires & & 20 \\
\hline 9 & Vero board & 1 & 300 \\
\hline 10 & PVC gear & 5 & 400 \\
\hline 11 & Mechanical setup & & 50 \\
\hline 12 & Lead \& rojon & & 500 \\
\hline 13 & Casing & & 25 \\
\hline 14 & Transportation cost & 1 & 8 \\
\hline 15 & USB hub port & 1 & \\
\hline 16 & Heat sink & & \\
\hline
\end{tabular}

The total cost is $1825 /=$ taka(Bangladeshi BDT).

\section{Discussion}

As the max output voltage of the charger is $4.96 \mathrm{v}$, so it is good to rotate gently the hand crank at an approx. speed 100 times per minute to produce the required voltage because the regulator reduces the voltage in $5 \mathrm{v}$. So, to minimize the stress on the muscles it should be cranked well but not more than 180 times per minutes. The casing used in this charger to setup its equipment is not good one as it is made of thin plain sheets. The used crank also not attached to the gear train firmly, so there us a chance of getting no outputs sometimes. If the fault is ignored somehow the charging device will nothing but the human power which is many times lost idly in doing nothing. The efficiency of the charger is good enough to provide charge to a $1300 \mathrm{mAh} \mathrm{Li}$-ion 
battery within a few moments. It takes few minutes to get some charge for the battery of cell phone. The device which is a portable charger will be cost effective if it is made in the factory for business purpose.

\section{Conclusion}

We have studied all possible alternative energy sources that can be used in emergency situations and finally wind up(hand crank) mechanism is the best option to generate voltage instantly and quite easily. Furthermore, the gear box train allows us to generate short amount of power through cranking. It is compact and rigid system, thus allows more portability. We used a small de generator as a generator in reverse operation. It's operational efficiency about 80 percent of its input, but through more cranking we can generate more sufficient voltage than required voltage. We constructed a device that can instantly generate power. But our device, based on gear train system is quite bulky, less portable and performs poorly to charge up the latest smart phones. We expected that the output voltage would be enough to charge up a simple Li-ion battery which has less current rating used in usual cell phones, we have succeeded in charging up such cell phone which has current rating less than the smart phones. We can achieve the success over the less current production by using a motor (which is used as generator) of better current rating. The mechanical set up we used in our device is not made according to the requirement as the device to be made small but it is still efficient of giving a good output for charging up cell phones. The goal we had set at the beginning of the project finally we have reached almost near to with some short comings.

\section{References}

[1]. Weston L. Moyers and H. Scott Coombe, Harvesting energy with Hand-Crank Generators to support dismounted soldier missions.

[2]. Nikhil Kumar Jain, V Aravind, Eranki V S Krishna Prasad and Y Kalyan Chakravarthy, Virtual prototype of mechanical hand crank mobile charger, IJITEE,ISSN: 2278-3075, Volume-2, Issue-2, January 2013

[3]. Thad Starner and Joseph A. Paradiso, Human generated power for Mobile Electronics.

[4]. Robert Dunn and Adam Weber, Hand crank generator for cell phones.

[5]. Ayush R Jain and Chinmay V Harmalkar, Hybrid mechanical charger, International Journal of Scientific \& Engineering, ISSN: 2229-5518, Research Volume 2, Issue 5,May-2011

[6]. Edwar Romeo, Energy harvesting: power at small scale.

[7]. Li Linqiang; A manual mobile phone charger; International Conference on Electrical and Control Engineering; Jun. 25-27, 2010, ISBN:978-1-4244-6880-5, p79-82.

[8]. Alfred Berrios, Tristan Byers, Melanie Cromer and Michael Matthews, Universal Charging Friend (U.C.F.)

[9]. Amitabha Ghosh and Ashok Kumar Malik, Theory of Mechanisms and Machines.ch. 9.

[10]. J. S. Brar and Dr. R. K. Bansal, Theory of Machines. ch. 10 pg. 450 - 460

[11]. C.K. Dyer. Fuel cells for portable applications. Journal of Power Sources, 106(1-2):3134,2002.

[12]. R.S. Khurmi, Theory of machines, 14th ed.; S. Chand \& Co. Ltd., New Dehli 2005;ISBN 9788121925242

[13]. http: www.technologystudent.com/gears1/geardex1.htm

[14]. http: en.wikipedia.org/wiki/Brushed DC electric motor 44

[15]. http: en.wikipedia.org/wiki/Brushless DC electric motor

[16]. http: en.wikipedia.org/wiki/Electromagnetic induction

[17]. http: en.wikipedia.org/wiki/Telephone magneto

[18]. http: en.wikipedia.org/wiki/Crank (mechanism)

[19]. http: en.wikipedia.org/wiki/Gear ratio

[20]. http: www.engineersedge.com/gear menu.shtml. 